\title{
A 24-year old man with persistent progressive breathlessness: early onset COPD
}

\author{
*Prem Parkash Guptaa, Dipti Agarwal ${ }^{\mathrm{b}}$ \\ a Professor of Respiratory Medicine and Chief of the COPD Clinic, Postgraduate Institute of Medical Sciences, Rohtak, India \\ ${ }^{\mathrm{b}}$ Assistant Professor of Physiology, Postgraduate Institute of Medical Sciences, Rohtak, India
}

Received 17th March 2007; accepted 22nd October 2007

\begin{abstract}
We describe the case of a 24-year old male who had been a heavy smoker since the age of 9 and who presented with an 8-year history of respiratory symptoms. He was having treatment for asthma. Spirometric studies and high-resolution computed tomography (HRCT) scans confirmed COPD with centrilobular emphysema. His blood level of alpha-1-antitrypsin was within the normal range. Early onset emphysema in smokers with a normal alpha-1-antitrypsin has been previously described. However, this case is, as far as we know, one of the youngest cases ever reported.

(C) 2007 General Practice Airways Group. All rights reserved

PP Gupta and D Agarwal. Prim Care Resp J 2007; 16(6): 387-390.

doi:10.3132/pcrj.2007.00082
\end{abstract}

Keyw ords COPD, emphysema, diagnosis, early onset, HRCT scan

\section{Case history}

A 24-year old man presented at our Institute with a history of progressive and persistent dyspnoea for the last eight years. He had intermittent episodes of cough that was mostly dry, occasionally associated with purulent sputum, and which later required antibiotic treatment. His symptoms had increased significantly over the 15 days prior to admission. There was no history of any chest pain, palpitation or pedal oedema. He denied any history of diabetes, hypertension, or any other significant disease. There was no history of any intravenous drug abuse. He started to smoke at the age of 9 and had smoked up to three packs of bidis (bidi is a form of cigarette without any filter, in which tobacco is rolled in a leaf rather than in paper) daily for the last 15 years. The patient was a farm worker and had received no formal education. He was a vegetarian and consumed alcohol occasionally.

Before he attended our Institute, he had consulted various family physicians. He was told he had bronchial asthma and had been treated accordingly but with only momentary relief. Moreover, his adherence to medications once acute symptoms were over was not adequate.

On examination, he had a good build but inadequate nutrition, weighing 40kg. He had tachypnoea along with tachycardia. Dry mucous membranes were noted but there was no focal neurological deficit. There was no cervical, supraclavicular, axillary, or inguinal lymphadenopathy. He had prominent costochondral junctions with less oblique ribs, a raised rib cage, deep supraclavicular fossae and a deep suprasternal notch (see Figure 1) suggestive of chronic respiratory insufficiency. Lungs were low-lying with decreased excursion and were hyper-resonant on percussion. He had bilateral wheezing over the lung fields. Cardiac examination revealed no abnormalities. The abdomen was soft and nontender and there was no organomegaly. No clubbing, oedema, or any skin lesions were noted.

Full blood count and routine biochemical tests, including blood sugar and urinalysis, were within normal limits. His serum was non-reactive for HIV antibodies. Posterio-anterior chest radiograph (PA CXR) revealed hyperinflated lung fields with a low-lying diaphragm and enlarged hilar vessels along with attenuated peripheral blood vessels and a tubular cardiac silhouette - see Figure 2A. The lateral view (Figure 2B) showed an increased retrosternal air space. The increased A$\mathrm{P}$ diameter, indicative of a barrel chest, was also seen.

\footnotetext{
* Corresponding author: Department of Respiratory Medicine, 9J/17, Medical Enclave, PGIMS, Rohtak, India, Pin 124001

Tel: 0091-1262-212666 E-mail: gparkas@yahoo.co.in
} 


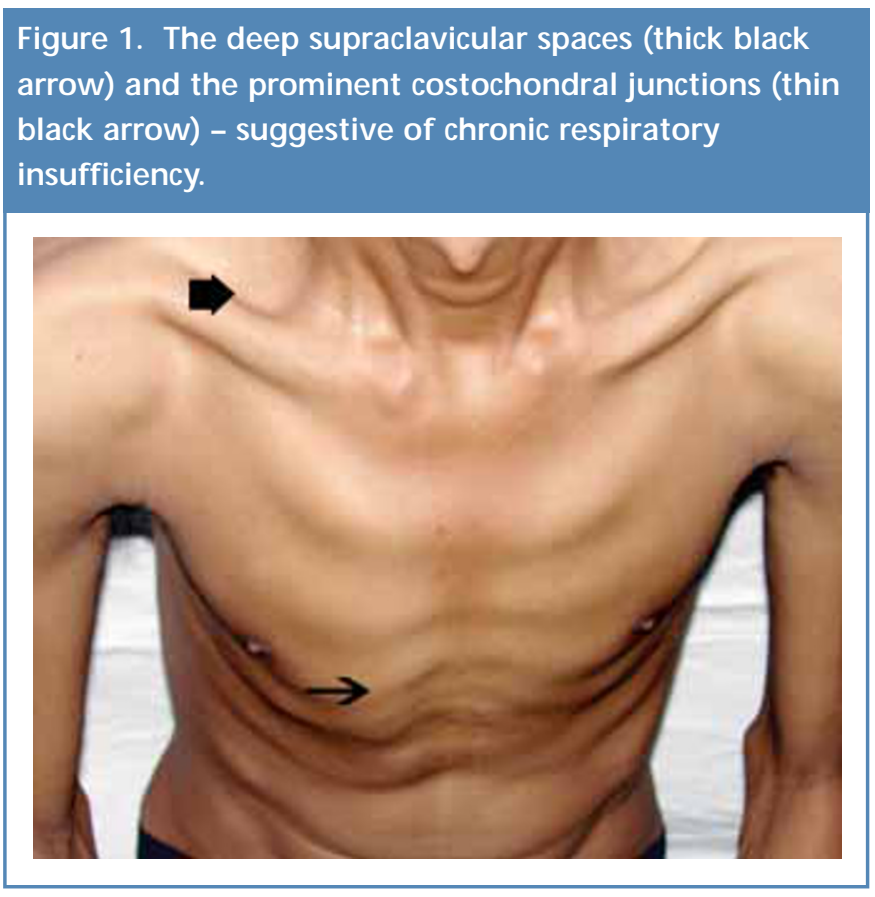

Spirometry was carried out on a Transfer Test Model ' $C$ ', P K Morgan, Chatham, Kent, UK as per American Thoracic Society recommendations. ${ }^{1}$ Spirometry results were suggestive of moderate chronic airflow obstruction with a prolonged expiratory phase: forced vital capacity $(\mathrm{FVC})=2.64$ I [predicted 4.29 I]; forced expiratory volume in half a second $\left(\mathrm{FEV}_{0.5}\right)=0.93 \mathrm{I}$ [predicted $3.35 \mathrm{I}$ ]; forced expiratory volume in one second $\left(\mathrm{FEV}_{1}\right)=1.39$ | [predicted 3.92 I]; $\mathrm{FEV}_{1} / \mathrm{FVC}$ ratio $=0.53 ; F_{25-75}=0.67 \mathrm{l} / \mathrm{s}$ [predicted $\left.4.67 \mathrm{l} / \mathrm{s}\right] ;$ peak expiratory flow $(\mathrm{PEF})=3.36 \mathrm{l} / \mathrm{s}$ [predicted $9.34 \mathrm{l} / \mathrm{s}$ ]; and FET = $6.09 \mathrm{~s}$. These indices confirm the presence of moderate airflow obstruction, small airways dysfunction, and a prolonged expiratory phase during the forced expiratory manoeuvre. Post-bronchodilator spirometry showed partially reversible airflow obstruction with an increase in $\mathrm{FEV}_{1}$ of only $8 \%$, much less than the reversible airflow obstruction seen in bronchial asthma.

High-resolution computed tomography (HRCT) scanning of the thorax was undertaken. It showed multiple emphysematous bullae in the apical segments of both upper lobes and paraseptal emphysema (Figures 3A \& 3B). The comparative increased A-P thoracic cage diameter was also seen. The lung parenchyma contained numerous small hyperlucent areas that were characteristic of centrilobular emphysema (Figure 3C). The medial basal segment of the right lower lobe (Figure 3D) was hyperlucent showing scarcity of blood vessels and vascular attenuation suggestive of emphysema. A close up of the axial HRCT section (Figure 4) clearly shows the centrilobular emphysema.

The patient was diagnosed as having chronic obstructive pulmonary disease (COPD) - largely emphysema - and as the patient was only 24 years old, blood was taken for alpha-1antitrypsin assay. This showed a normal level of $160 \mathrm{mg} / \mathrm{dl}$. Given this normal value, genetic blood testing for alpha-1antitrypsin deficiency disease was not carried out as it was not indicated and also because of its expense.

The patient was treated with oxygen therapy, nebulisation

Figure 2. Chest radiographs: (A) PA view depicting hyper-inflated bilateral lung fields with a low-lying diaphragm, attenuated peripheral blood vessels and a tubular cardiac silhouette; (B) lateral view showing an increased retrosternal air space and also an increased A-P diameter.
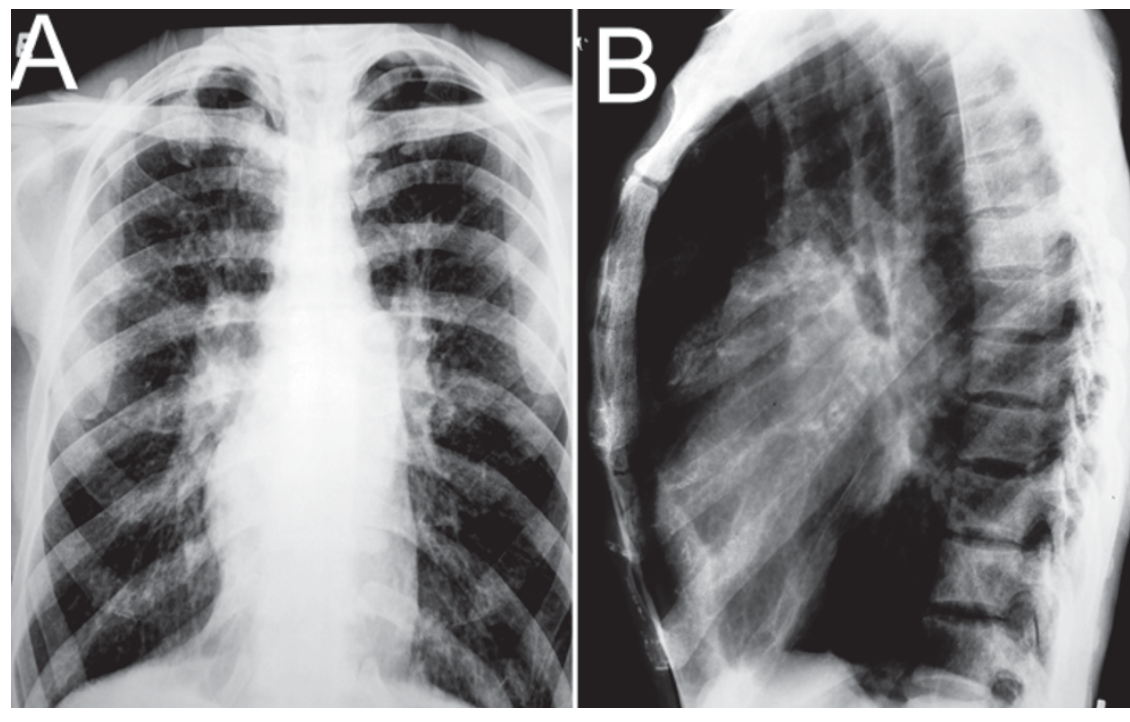
Figure 3. HRCT thorax scans showing multiple emphysematous bullae in apical segments of both upper lobes (A and B) at different sections. (C) HRCT thorax revealing small hyperlucent areas (white arrows) suggestive of centrilobular emphysema; (D) medial basal segment of right lower lobe was hyperlucent with scarcity of blood vessels suggestive of emphysema.

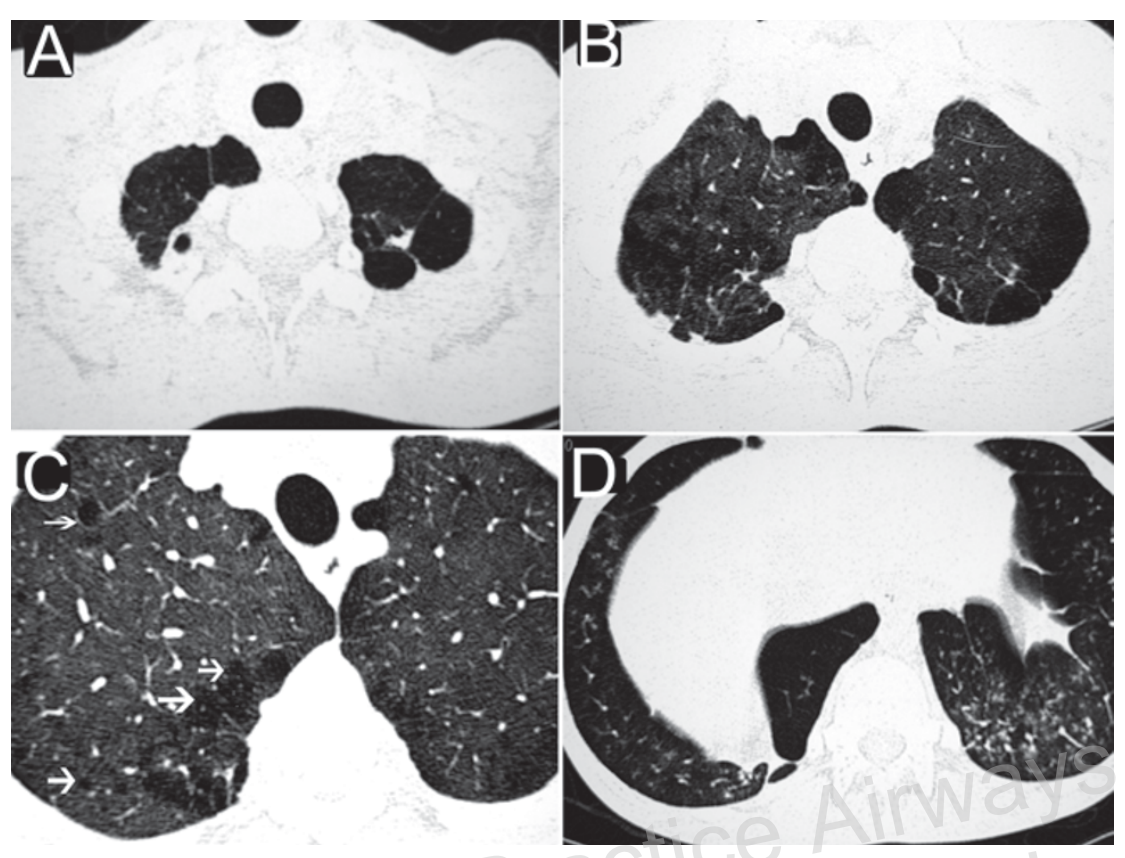

Figure 4. A close up of the HRCT thorax axial section showing centrilobular emphysema.

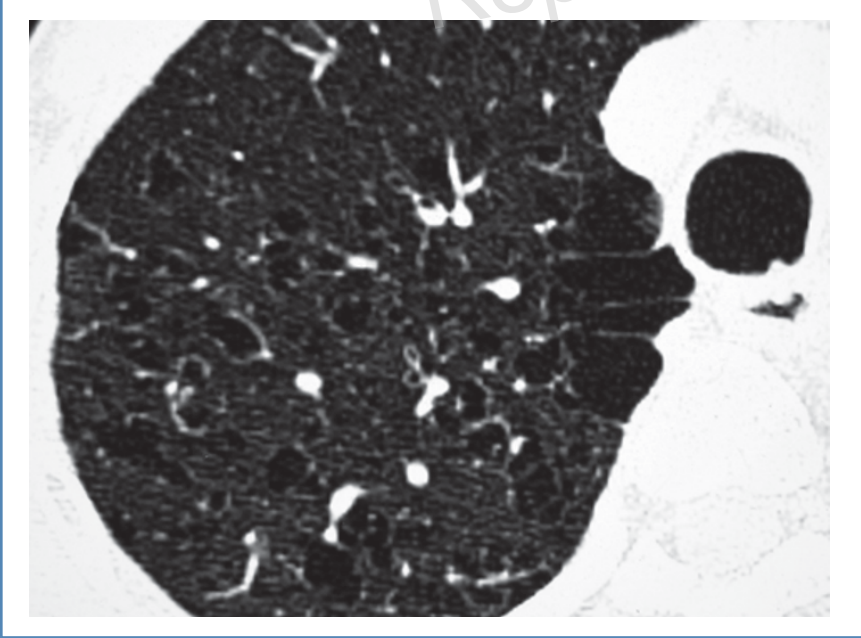

with salbutamol, budesonide and ipratropium bromide, and was given supportive therapy including intravenous fluids, antibiotics and mucokinetics. Once stabilised, he was prescribed a metered dose inhaler (MDI) containing a combination of tiotropium and formoterol to be taken with a spacer, and was advised to attend the COPD clinic and antismoking clinic at our Institute. He has regular follow-up and his illness is now stable. He has given up smoking completely, after medical education and a strong non-ambiguous recommendation.

\section{Final diagnosis}

COPD with centrilobular emphysema.

\section{Discussion}

COPD is a preventable and treatable disease with some significant extrapulmonary effects that may contribute to the severity in individual patients. Its pulmonary component is characterised by airflow limitation that is not fully reversible. The airflow limitation is usually progressive and associated with an abnormal inflammatory response of the lung to noxious particles or gases. ${ }^{2}$ The chronic airflow limitation characteristic of COPD is caused by a combination of small airway disease (obstructive bronchiolitis) and parenchymal destruction (emphysema), the relative contributions of which vary from person to person.

Smoking is the most significant risk factor for COPD; approximately $85 \%$ of all cases are attributed to cigarette smoking. Cigarette smokers have a higher prevalence of respiratory symptoms and lung function abnormalities, a greater annual rate of decline in $\mathrm{FEV}_{1}$, and a greater COPD mortality rate than non-smokers. ${ }^{2}$ However, the onset of typical, smokingrelated emphysema is in the 6 th to 8 th decades of life. ${ }^{2}$ 
Box 1. Risk of emphysema at various serum levels of alpha-1-antitrypsin

\begin{tabular}{|c|c|c|c|c|}
\hline $\begin{array}{c}\text { Prevalence } \\
\%\end{array}$ & $\begin{array}{l}\text { Serum } \\
\text { level } \\
\mathrm{mmol} / \mathrm{l}\end{array}$ & $\begin{array}{l}\text { Serum } \\
\text { level } \\
\mathrm{mg} / \mathrm{dl}\end{array}$ & Genotype & $\begin{array}{c}\text { Risk of } \\
\text { emphysema }\end{array}$ \\
\hline 91 & $20-53$ & $150-350$ & MM & No increase \\
\hline 6.1 & $18-52$ & $110-340$ & MS & No increase \\
\hline 2.7 & $17-33$ & $90-210$ & $M Z$ & No increase \\
\hline 0.1 & $15-33$ & $100-200$ & SS & No increase \\
\hline 0.1 & $8-16$ & $75-120$ & $S Z$ & $\begin{array}{c}\text { Mild increase } \\
\text { (Emphysema risk } \\
20-50 \% \text { ) }\end{array}$ \\
\hline 0.02 & $2-7$ & $20-45$ & ZZ & $\begin{array}{l}\text { Highly increased } \\
\text { (Emphysema risk } \\
\text { 80-100\%) }\end{array}$ \\
\hline$<0.01$ & 0 & 0 & Null-Null & $\begin{array}{c}\text { Extremely increased } \\
\text { (Emphysema risk } \\
100 \%)\end{array}$ \\
\hline
\end{tabular}

$\mathrm{M}=$ normal allele; $\mathrm{Z}=$ dysfunctional allele; $\mathrm{S}=$ deficient allele; null $=$ no detectable serum levels of alpha-1-antitrypsin

The other main established risk factor for the development of chronic obstructive pulmonary disease is deficiency of alpha1 -antitrypsin, a rare genetic defect that is present in less than $1 \%$ of all cases. ${ }^{3}$ There are isolated case reports describing earlyonset emphysema in young patients without a significant smoking history and with a normal alpha-1-antitrypsin level. ${ }^{4,5}$ These suggest that other genetic and environmental risk factors may also play role in the development of emphysema. In one report, seven young patients with previous intravenous ritalin abuse were diagnosed as having severe panlobular (panacinar) emphysema particularly in the lower lung zones, and five of the seven patients who were tested for alpha-1-antitrypsin deficiency had normal levels. ${ }^{6}$ Emphysema has been described in three women aged 39, 41 and 41 years who were all heavy smokers.? Severe alpha-1-antitrypsin deficiency can affect the lungs, liver, and skin. Patients with alpha-1-antitrypsin deficiency tend to present with emphysema in the fourth to fifth decades of life and they often present with liver disease as children. ${ }^{3}$ The condition is inherited as an autosomal co-dominant disorder and is characterised by serum (and hence, lung) levels of alpha-1antitrypsin far below the laboratory reference range of 20-50 $\mathrm{mmol} / \mathrm{L}$ (see Box 1). ${ }^{8}$

\section{Box 2. Learning points}

1. Chronic airflow obstruction in young subjects below the age of 30 is usually labelled as bronchial asthma since this is by far the commonest aetiology. However, in rare cases, the airflow limitation might be irreversible or partially reversible, and after careful investigation may fit with a diagnosis of COPD.

2. HRCT is helpful in documenting the diagnosis of, and sub-typing, emphysema in young patients with airflow limitation.

Chronic airflow limitation in young subjects is usually diagnosed as bronchial asthma - as was the case with the present patient. Published literature has suggested that early onset emphysema in the absence of a genetic deficiency of alpha-1-antitrypsin is not so rare. However, this case is the youngest one documented, and it suggests that the extent of the smoking history rather than just the age of the patient per se is also significant.

The significant learning points from this Case report are shown in Box 2.

\section{Conflict of interest declaration}

None declared.

\section{References}

1. Brusasco V, Gapo R, Viegi G. Standardization of spirometry. Series "ATS/ ERS task force: standardization of lung function testing". Eur Resp J 2005;26:31938.

2. Global Initiative for Chronic Obstructive Lung Disease. Executive Summary: Global Strategy for the Diagnosis, Management, and Prevention of COPD, December 2006. Available at: http://goldcopd.com/Guidelineitem. Accessed on January 15; 2007

3. Dwomiczak S, Ziora D, Konofalski L, Szalaty M, Kowalska A, Kozielski J. Analysis of alpha-1-antitrypsin phenotypes and genotypes in patients with early-onset pulmonary emphysema. Pneumonol Alergol Pol 2005;73:12-17.

4. Kim V, Kueppers F, D'Alonzo GE Jr. Severe, early-onset emphysema with normal alphal-antitrypsin levels in nonsmokers: a clinical dilemma. COPD 2004;1:31319.

5. Habenstein KR, Roy TM, Fields CL. Pulmonary emphysema in a nonsmoker with normal alpha-1-antitrypsin. J Ky Med Assoc 1992;90:327-3.

6. Schmidt RA, Glenny RW, Godwin JD, Hampson NB, Cantino ME, Reichenbach DD. Panlobular emphysema in young intravenous Ritalin abusers. Am Rev Respir Dis 1991;143:649-56.

7. de Fraiture DM, Roldaan AC. Severe chronic obstructive pulmonary disease in young women who smoke. Ned Tijdschr Geneeskd 2003;147:2261-5.

8. ClinLab Navigator. Alpha 1 Antitrypsin: Test interpretation. Available at: http://www.clinlabnavigator.com/Tests/Alpha1Antitrypsin.html. Accessed on September 11, 2007

\section{Available online at http://w w w.thepcrj.org}

